\title{
Net precipitation over the Baltic Sea during present and future climate conditions
}

\author{
Anna Rutgersson*, Anders Omstedt, Jouni Räisänen
}

Rossby Centre, SMHI, 60176 Norrköping, Sweden

\begin{abstract}
By using a process-oriented ocean model forced with data from a gridded synoptic database, net precipitation values (precipitation minus evaporation) over the Baltic Sea are obtained. For a range of realistic meteorological forcing the average annual value obtained from an $18 \mathrm{yr}$ (1981-1998) simulation ranges between 1100 and $2500 \mathrm{~m}^{3} \mathrm{~s}^{-1}$. The monthly variations are significant with the highest values occurring in early summer and even negative values in late autumn. Ice is an important factor, and the net precipitation is close to zero in the southern basins with no ice. Calculated net precipitation for a 98 yr period (1901-1998) using river runoff and maximum ice extent indicates that the investigated $18 \mathrm{yr}$ period was wetter than the almost $100 \mathrm{yr}$ climate mean. A realistic climate estimate of net precipitation during the 20th century is estimated to be $1500 \pm 1000 \mathrm{~m}^{3} \mathrm{~s}^{-1}$. The evaluation of 2 present day regional climate simulations indicated high precipitation, low evaporation, and thus excessive net precipitation compared to the climate estimate from this investigation. When simulating the effect of increased greenhouse gases, the change in net precipitation was positive but small due to the compensating effects of increased precipitation and increased evaporation associated with increased temperature and reduced ice.
\end{abstract}

KEY WORDS: Water cycle $\cdot$ Baltic Sea $\cdot$ Precipitation $\cdot$ Evaporation $\cdot$ Climate

Resale or republication not permitted without written consent of the publisher

\section{INTRODUCTION}

The transport of freshwater between the atmosphere and the ocean plays an important role in the climate system, both in terms of the water cycle and the heat balance. The latent heat flux from the oceans to the atmosphere is one of the largest heat sources for the atmosphere. Evaporation also plays an important role in the ocean since it weakens ocean stratification. Dense water masses may form which can sink and ventilate deep and intermediate water layers. Precipitation, on the other hand, decreases surface salinity and stabilises the upper ocean.

The need for a better understanding of the energy and water cycles in the climate system has generated several international research programmes in which

*E-mail: anna.rutgersson@smhi.se
GEWEX (The Global Energy and Water Experiment) is an important sub-program within the World Climate Research Program. Six continental-scale experiments have been initiated within GEWEX, with the primary goal being to improve the understanding of energy and water cycles in different climate zones. One of these experiments is BALTEX (the Baltic Sea Experiment; BALTEX 1995, Raschke et al. 2001), which aims to develop and validate coupled regional models and investigate the climate of the Baltic drainage basin in relation to large-scale atmospheric circulation.

A major focus for research within BALTEX is to quantify and model net precipitation over the land as well as the Baltic Sea. In the current work we focus on the net precipitation (precipitation minus evaporation) over the Baltic Sea. The net precipitation over the Baltic Sea, the freshwater inflows from river runoff and the in- and outflows through the Baltic Sea entrance 
are the main components in the hydrological cycle of the Baltic Sea (Omstedt \& Rutgersson 2000). Various aspects of this cycle have been investigated for over $100 \mathrm{yr}$, starting with the pioneering work of Knudsen $(1899,1900)$. Several of the earlier estimates related to the hydrological cycle of the Baltic Sea are reviewed in HELCOM (1986). New improved estimates have been developed over the last decade, partly within the BALTEX program, and some of these results are reviewed in Raschke et al. (2001). The new estimates are based on the use of new data and new instruments, and the use of models when calculating the energy and water cycles.

The current work investigates the net precipitation over an 18 yr period using a gridded meteorological database and a process-oriented ocean model, PROBEBaltic (Omstedt \& Nyberg 1996). Using an ocean model when investigating heat and water cycles is an important improvement over earlier studies, as the cycles are solved in a consistent way. The results can be checked with regard to sea-surface temperatures, ice, in- and out-flow properties through the Baltic entrance area, and the salinity (freshwater content) of the system. The method was earlier used by Omstedt et al. (1997). Later it was found that the parameterisation used for the sensible and latent heat fluxes needed to be improved, and new formulations were introduced (Rutgersson et al. 2001a). In the current work these new formulations are used for an extended period, and a sensitivity analysis for the meteorological forcing is introduced.

First we establish the climate conditions valid for an $18 \mathrm{yr}$ period (1981-1998). To put the investigated $18 \mathrm{yr}$ period in perspective, a simple relation between net precipitation, river runoff, and maximum ice extent is established, and the net precipitation over the entire 20th century is investigated. We then analyse the results from the Rossby Centre regional climate model with regard both to current climate conditions and to possible future climate change.

The outline of the present work is as follows: The next section presents the method for calculating the meteorological forcing of the Baltic Sea model including precipitation, together with a short presentation of the Baltic Sea model. Section 3 introduces some validation calculations related to sea-surface temperatures and sea ice. The results from calculating net precipitation for the 1981-1998 period are then given together with a sensitivity analysis in Section 4 . We also establish a relation between net precipitation, river runoff, and maximum ice extent, and use the time series of the 2 latter parameters to estimate net precipitation from 1901-1998. In Section 5, possible future changes in net precipitation are addressed by investigating the results of the Rossby Centre regional climate model. Finally a discussion with some conclusions appears in Section 6.

\section{METHOD}

\subsection{Meteorological forcing and estimated errors}

The meteorological forcing of the Baltic Sea model was extracted from a gridded database developed at SMHI (Swedish Meteorological and Hydrological Institute). The database covers the Baltic Sea drainage basin with a grid of $(1 \times 1)^{\circ}$ grid squares and uses all available synoptic weather stations in the area. A grid of $(1 \times 1)^{\circ}$ gives a grid size of more than $100 \mathrm{~km}$ and 4 to 5 grid points across the Baltic Sea from the Swedish coast to the Baltic states. There are generally 700 to 800 observations twice daily in the Nordic region. These are interpolated in space using optimum interpolation. A quality-control algorithm was built into the objective analysis scheme to reject erroneous observations. No correction was made for precipitation losses at high wind speeds at the synoptic stations used in the $\operatorname{SMHI}(1 \times 1)^{\circ}$ database. Only geostrophic wind is available in the $\mathrm{SMHI}$ database, and it is reduced to the $10 \mathrm{~m}$ level using a statistical relation according to Omstedt \& Axell (pers. comm.). In Fig. 1 an example from 1998 of the distribution of the synoptic stations in the $\mathrm{SMHI}(1 \times 1)^{\circ}$ database is shown. As the database is strongly influenced by land, the air temperature is corrected by considering the water temperature (A. Omstedt \& L. B. Axell pers. comm.). However, also in other parameters the database can be assumed to be influenced by land surfaces, since the majority of stations are situated on land and in coastal regions.

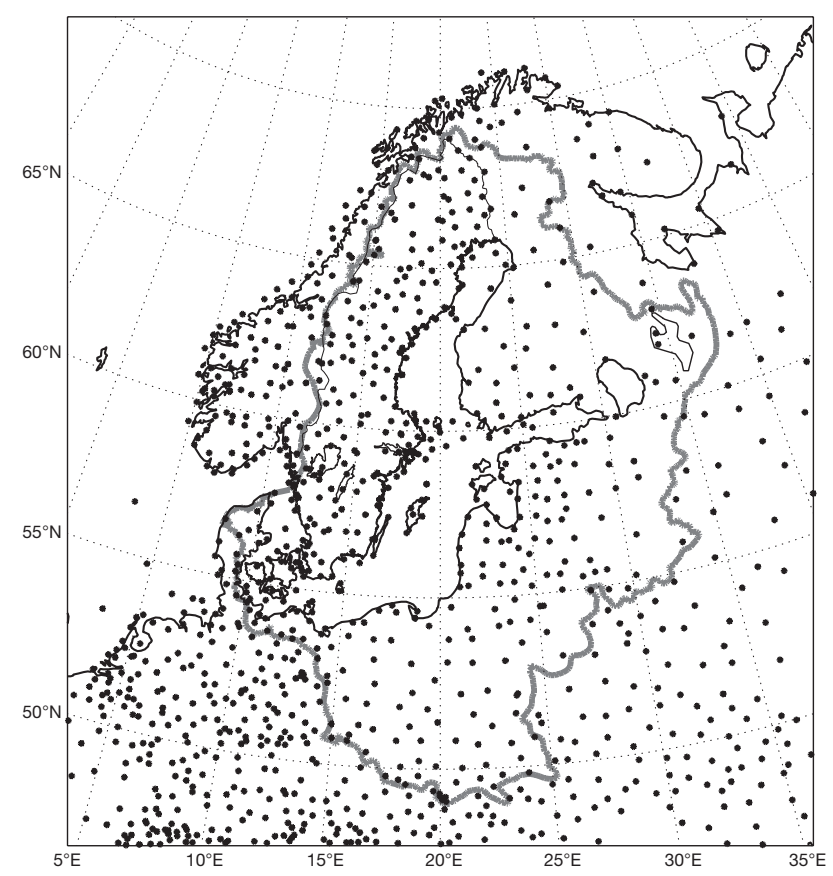

Fig. 1 . The area of the SMHI $(1 \times 1)^{\circ}$ database and an example of the distribution of synoptic stations in the area. The Baltic Sea drainage basin is also shown (grey line) 
The accuracy of some of the parameters in the $\mathrm{SMHI}(1 \times 1)^{\circ}$ database was investigated in Rutgersson et al. (2001a) for an 8 mo period (May-December 1998). Grid-point values from the database are compared with mast measurements from 2 carefully checked masts, one east of Gotland (Östergarnsholm) and one north-east of Bornholm (Christiansø); see A and B in Fig. 2. The results are shown in Table 1. The database overestimates the average wind speed by maximum $1 \mathrm{~m} \mathrm{~s}^{-1}$, while humidity and temperature are underestimated by up to $1^{\circ} \mathrm{C}$ and $1 \mathrm{~g} \mathrm{~kg}^{-1}$, respectively. Other deficiencies in the meteorological data can be expected to occur in cloudiness and in precipitation. In a satellite study Karlsson (2000) showed a significant difference in cloudiness between land and the Baltic Sea for the period 1991-1998. Cloud frequencies were typically 10 to $20 \%$ lower over sea than over land during the summer. Assuming that the $\operatorname{SMHI}(1 \times 1)^{\circ}$ database is biased with too much land influence, cloudiness may actually have been smaller than that used for the forcing of PROBE-Baltic. In Rutgersson et al. $(2001 b)$ the precipitation in the $\operatorname{SMHI}(1 \times 1)^{\circ}$ database is investigated, and it can be assumed that the precipitation is low because of the uncorrected synoptic gauges used in $\mathrm{SMHI}(1 \times 1)^{\circ}$. Thus it would be realistic to increase precipitation by $10 \%$.

In Section 4 these estimated errors are taken as a starting point for a sensitivity study of net precipitation. The impact of these possible observational errors on the net precipitation are examined one by one, and the following cases are investigated: (1) temperature increase by $1^{\circ} \mathrm{C}(T+1)$; (2) humidity increase by $1 \mathrm{~g}$ $\mathrm{kg}^{-1}(q+1) ;(3)$ a wind reduction of $1 \mathrm{~m} \mathrm{~s}^{-1}(U-1)$; (4) decrease in cloudiness by $10 \%(0.9 c l)$; and (5) increase in precipitation by $10 \%(1.1 P)$.

Table 1. Statistics for comparison of the mean meteorological parameters from mast data at Christiansø and Östergarnsholm with the SMHI $(1 \times 1)^{\circ}$ database at the nearest grid point. $U$ : wind speed; $T$ : temperature; $q$ : humidity; $\mathrm{r}_{0}$ : correlation coefficient; bias: averaged difference $\left[\operatorname{SMHI}(1 \times 1)^{\circ}\right.$ minus directly measured]; rms: root-mean-square error; $\mathrm{n}$ : number of hourly values used for the statistics

\begin{tabular}{|lccc|}
\hline & $U\left(\mathrm{~m} \mathrm{~s}^{-1}\right)$ & $T\left({ }^{\circ} \mathrm{C}\right)$ & $q\left(\mathrm{~g} \mathrm{~kg}^{-1}\right)$ \\
\hline Christiansø & & & \\
$\mathrm{r}_{0}$ & 0.89 & 0.94 & 0.95 \\
Bias & 1.0 & -1.2 & -0.8 \\
$\mathrm{rms}$ & 1.9 & 2.2 & 1.1 \\
$\mathrm{n}$ & 2639 & 2026 & 344 \\
Östergarnsholm & & & \\
$\mathrm{r}_{0}$ & 0.82 & 0.97 & 0.97 \\
Bias & 0.1 & -0.0 & 0.2 \\
rms & 1.7 & 1.2 & 0.7 \\
$\mathrm{n}$ & 918 & 918 & 902 \\
\hline
\end{tabular}

\subsection{River runoff and annual maximum ice extent}

In the river runoff data, the total runoff to the Baltic Sea is given as monthly means. The data for the period 1950-1998 are based on river runoff data collected by the BALTEX Hydrological Data Centre at SMHI (Bergström \& Carlsson 1994). For the periods 1901-1920 and 1921-1949, we used data from Cyberski \& Wroblewski (2000) and Mikulski (1982) respectively.

Representing ice in the Baltic Sea we use the data on annual maximum ice extent collected by the Finnish Institute of Marine Research (Seinä \& Palosuo 1993). These data illustrate a large interannual variability. Minimum observed values were $52 \times 10^{3} \mathrm{~km}^{2}$, with ice only in the Bothnian Bay and Gulf of Finland; the mean value was $217 \times 10^{3} \mathrm{~km}^{2}$; the maximum observed ice extent value was $420 \times 10^{3} \mathrm{~km}^{2}$, when nearly the entire Baltic Sea was covered. According to A. Seinä (pers. comm. 2000) the estimated error in maximum ice extent during the studied period is $\pm 5 \%$. This data series goes back to 1720 and has been recently analysed by Omstedt \& Chen (2001). The reader is referred to that paper for further details concerning the ice data.

\subsection{The Baltic Sea model}

The Baltic Sea model PROBE-Baltic (Omstedt \& Nyberg 1996, Omstedt \& Axell 1998) divides the water body into sub-basins based upon coastlines and bottom topography (Fig. 2). The modelling approach is process-oriented, focusing on the conservation properties of heat, ice, water and salt. The area-depth distribution is considered in all sub-basins. The properties in each sub-basin are calculated in terms of horizontal mean values of temperature, salinity, and ice-cover and ice-thickness making use of the $k-\varepsilon$ turbulence model and including a simple parameterisation of deep water mixing. Each sub-basin is coupled to surrounding sub-basins with horizontal flows that are parameterised based on strait flow dynamics. The coupling between water and atmosphere is through momentum and heat flux parameterisations using bulk formulas for sensible heat flux, latent heat flux, net long-wave radiation and solar radiation. The sensible heat, latent heat and momentum fluxes are calculated using neutral coefficients from WAMDI (1988) and DeCosmo et al. (1996) and a stability coefficient from Launiainen (1995), as described in Rutgersson et al. (2001a). In Omstedt (1990), the parameterisations used in the net long-wave radiation and the short-wave radiation during open and ice-covered conditions are given.

In the ice modelling both dynamical and thermodynamic processes as formation, growth, melting and ice 


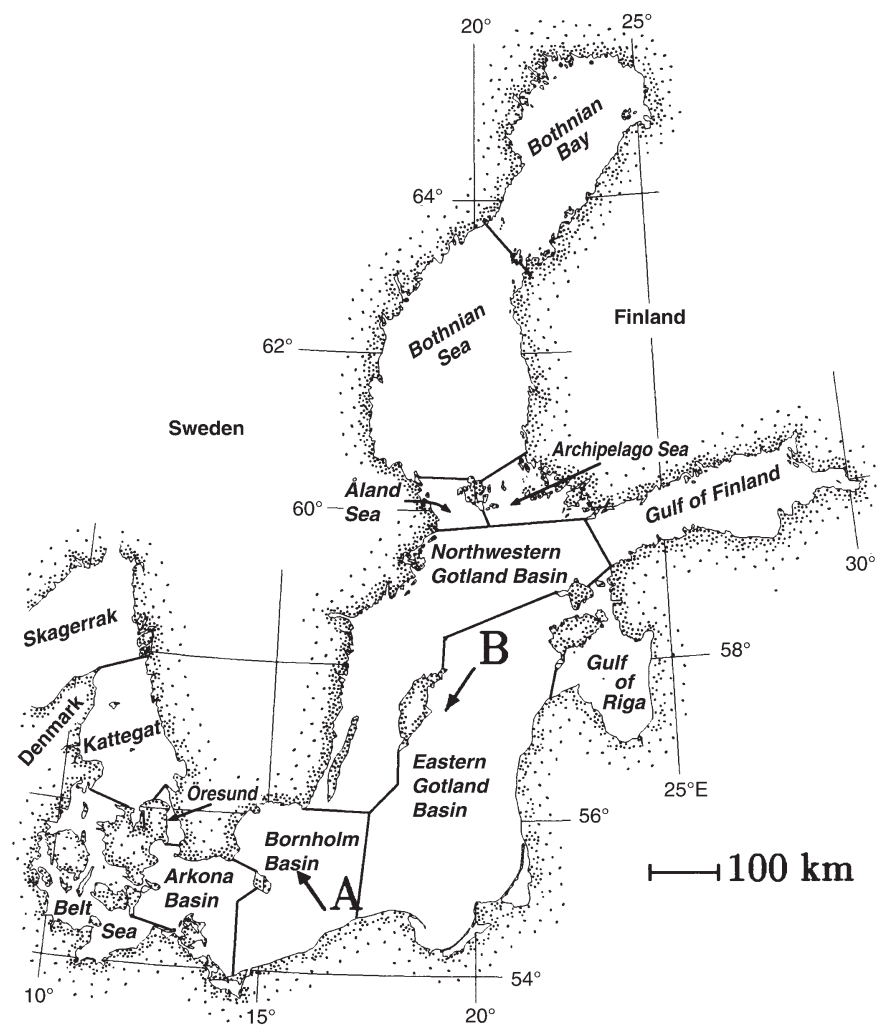

Fig. 2. The division of the Baltic Sea into basins used in PROBE-Baltic. 3 = Arkona Basin and Öresund (AR), 4 = Bornholm Basin (BH), 5 = Eastern Gotland Basin (EG), 6 = Northwestern Gotland Basin (NWG), 7 = Gulf of Riga (GR), 8 = Gulf of Finland (GF), 9 = Bothnian Sea, Archipelago Sea and Åland Sea (BS), $10=$ Bothnian Bay (BB). Measuring sites: $\mathrm{A}=$ Christiansø, $\mathrm{B}=$ Östergarnsholm

ridging are included. Only ridging associated with onshore ice drift is considered and off-shore ice drift is assumed to move as free wind-forced ice drift. River runoff is included as observed monthly means (see Section 2.2), and sea level variations in the Kattegat are based upon observed daily means from 1 water level station in the Kattegat (Viken). Besides river runoff and sea level data from the Kattegat, the model is forced by meteorological information on wind, air temperature, humidity and total cloudiness (see Section 2.1). The time resolution of the meteorological data is $3 \mathrm{~h}$.

\section{BALTIC SEA RESPONSE TO APPLIED FORCING}

\subsection{Sea-surface temperatures}

When estimating the net precipitation over the Baltic Sea, one needs information on both precipitation and evaporation. The precipitation rates are taken from the gridded meteorological database, while the evaporation rates are calculated from the ocean model. The model is used in a number of sensitivity tests, and before analysing net precipitation we analysed the quality of the ocean model calculations. In Fig. 3 and Table 2, the simulated sea-surface temperatures (SST) from the sensitivity calculations are compared with observed SSTs. The SSTs are analysed for 3 of the sub-basins in Fig. 2. All measurements of SSTs are taken from high-quality research vessel observations. It was found that the SSTs were generally modelled very skilfully, and that the range of sensitivity runs does not deviate unrealistically from observations. The agreement with the Bornholm Basin (SST-BH) is good in the reference case, whereas the SST is slightly too low in the Eastern Gotland Basin (SST-EG). The only basin which shows major improvement in the sensitivity analysis is the Bothnian Sea (SST-BS), which is too cold in the reference case. Using a higher air temperature or higher humidity reduces the upward heat fluxes, causing the SST to correspond more closely to the measurements. The cold bias is especially clear during winter with low SST. In Fig. 3 it is important to note that the data coverage is low in the winter in the northern basin. The investigated range of forcing covers reasonably well the difference between measured SST and the model simulations in all 3 basins. As a whole, the reference run agrees most closely with the measured data.

\subsection{Annual maximum ice extent}

The model simulations are also validated using observed maximum ice extent (Fig. 4). The reference calculation follows the observed data reasonably well. However, during mild winters, the reference run over-

Table 2. Validation of the SST from 3 basins for the different sensitivity tests. Measured SST data is from research vessel observations. SST-BH: Stn BY5 in the Bornholm Basin; SST-EG: Stn BY15 in the Eastern Gotland Basin; SST-BS: Stn US5B in the Bothnian Sea. The different basins are shown in Fig. 2

\begin{tabular}{|c|c|c|c|c|c|c|}
\hline & Reference & $T+1$ & $q+1$ & $U-1$ & $0.9 c l$ & $1.1 P$ \\
\hline \multicolumn{7}{|c|}{ SST-BH $\left({ }^{\circ} \mathrm{C}\right)(\mathrm{n}=344)$} \\
\hline Bias & -0.14 & 1.24 & 1.17 & 0.15 & 0.01 & -0.14 \\
\hline $\mathrm{rms}$ & 0.92 & 1.53 & 1.50 & 0.92 & 0.83 & 0.92 \\
\hline \multicolumn{7}{|c|}{ SST-EG $\left({ }^{\circ} \mathrm{C}\right)(\mathrm{n}=204)$} \\
\hline Bias & -0.55 & 0.72 & 0.66 & -0.10 & -0.42 & -0.55 \\
\hline $\mathrm{rms}$ & 1.11 & 1.32 & 1.26 & 1.02 & 1.08 & 1.11 \\
\hline \multicolumn{7}{|c|}{ SST-BS $\left({ }^{\circ} \mathrm{C}\right)(\mathrm{n}=135)$} \\
\hline Bias & -1.40 & -0.20 & -0.28 & -1.03 & -1.21 & -1.39 \\
\hline $\mathrm{rms}$ & 1.75 & 1.16 & 1.09 & 1.55 & 1.63 & 1.75 \\
\hline
\end{tabular}



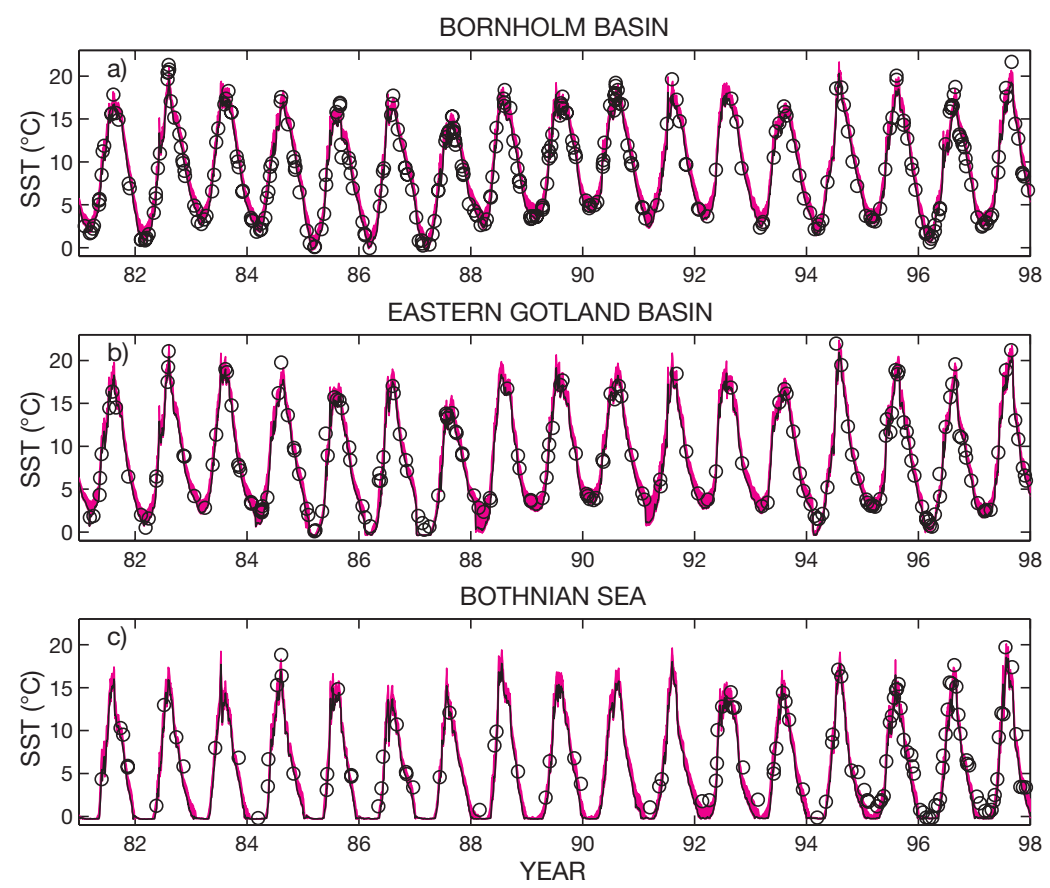

Fig. 3. Sea-surface temperatures (SSTs) from sea cruises (circles) and from the reference simulation (solid lines). Red areas show the range of the sensitivity tests. Three basins are shown: (a) Bornholm Basin, (b) Eastern Gotland Basin and (c) Bothnian Sea

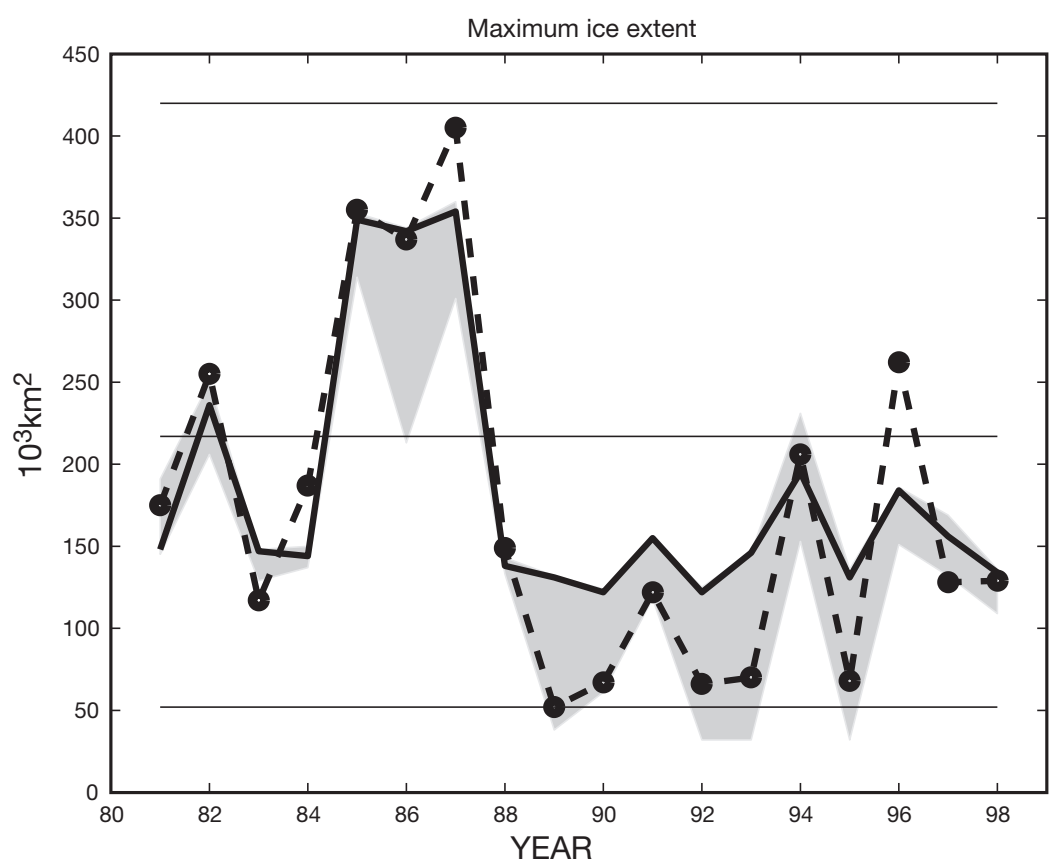

Fig. 4. Maximum ice cover over the Baltic Sea from observations and simulations. Thick solid line: reference PROBE-Baltic simulation; shaded area: the range of different forcing. Thick dashed line: derived from observations. Thin straight lines: minimum $\left(52 \times 10^{3} \mathrm{~km}^{2}\right)$, mean (from 1720-1998; $217 \times 10^{3} \mathrm{~km}^{2}$ ), and maximum $\left(420 \times 10^{3} \mathrm{~km}^{2}\right)$ observed ice extent estimated the extent of ice. Most of the sensitivity runs show less ice than the reference case, improving the agreement for mild winters, but not for cold.

The observed mean value for the investigated period $\left(175 \times 10^{3} \mathrm{~km}^{2}\right)$ is lower than the climate mean valid for 1720-1998 (see Section 2.2), indicating a period with relatively mild winters. In particular, the last part of our 18 yr period (from 1988) was dominated by a positive phase of the North Atlantic Oscillation (NAO), which is usually associated with westerly winds and mild winters in Northern Europe. The influence of atmospheric circulation on the maximum ice extent was recently analysed by Omstedt \& Chen (2001), where further details about sea ice in the Baltic Sea can be found. The work treated the sensitivity of the ice extent to changes in air temperature and the relationship between ice extent and largescale circulation. The analyses showed, for example, a fairly high correlation with the NAO index during winter.

In Table 3 the observed maximum ice extent is compared with the different model simulations. For the maximum ice extent, all of the runs give relatively similar results, except for the increased humidity case, which clearly shows an ice extent that is too small. We conclude from these calculations that the long-term ice extent is realistically modelled in the reference run (within an error of less than $10 \%$ ) and that the sensitivity runs do not deviate too far from observed values.

Both modelled SST and maximum sea ice extent agree relatively well with measured data, which gives us confidence in using the model for investigations of net precipitation. The reference run gives the best agreement with measured data, but the data coverage is low, and the different sensitivity tests cannot be judged unrealistically on the basis of these SST and ice comparisons alone.

\section{NET PRECIPITATION DURING PRESENT CLIMATE CONDITIONS}

Net precipitation is probably the least known component of the water balance of the Baltic Sea. This section aims to establish an estimate of present-day net precipitation, including the error bounds of this estimate. 
Table 3. Observed and modelled maximum ice extent, $A_{\text {ice }}$ with the different meteorological forcings. The observed maximum ice cover is from ice charts. cl: cloudiness; $P$ : precipitation

\begin{tabular}{lcccccc|}
\hline & Reference & $T+1$ & $q+1$ & $U-1$ & $0.9 c l$ & $1.1 P$ \\
\hline Bias & 10 & -14 & -40 & 13 & -14 & 10 \\
rms & 45 & 44 & 55 & 45 & 46 & 45 \\
\hline
\end{tabular}

In Section 5 we will use these results to investigate net precipitation modelled by a regional climate model.

We examined the calculated net precipitation during the $18 \mathrm{yr}$ period from 1981 to 1998 using the meteorological database and the ocean model simulations. The sensitivity of precipitation, evaporation and net precipitation are examined, based on estimated errors in the meteorological forcing, and annual, seasonal, and regional variations are analysed. To put the investigated 18 yr period in perspective, a simple relation between net precipitation, river runoff and maximum ice extent is established and the net precipitation during almost a $100 \mathrm{yr}$ period, from 1901 to 1998, is investigated. Based on these calculations, the range in which net precipitation over the Baltic Sea has varied during present climate conditions is estimated.

\subsection{8 yr mean values}

The calculated $18 \mathrm{yr}$ mean values of precipitation $(P)$, evaporation $(E)$ and net precipitation $(P-E)$ are given in Table 4 . As one would expect, $P-E$ is mainly sensitive to changes in the values of $q$ and $P$. Both the case $q+1$ and the case $1.1 P$ result in a significant increase in $P-E$. Temperature is also important, especially when the specific humidity is calculated from the relative humidity, as is the case here (thus both $T$ and $q$ are changed in $T+1$ ). With increased temperature the net precipitation decreases. Changing wind speed and

Table 4. Averages for the $18 \mathrm{yr}$ period of the sensitivity tests. The reference case uses the meteorological forcing from the $\mathrm{SMHI}(1 \times 1)^{\circ}$ database. $P$ : precipitation; $E$ : evaporation; $P-E$ : net precipitation. $T+1$ : temperature increased by $1^{\circ} \mathrm{C} ; q+1$ : humidity increased by $1 \mathrm{~g} \mathrm{~kg}^{-1} ; U-1$ : wind speed decreased by $1 \mathrm{~m} \mathrm{~s}^{-1} ; 0.9 \mathrm{cl}$ : cloudiness decreased by $10 \% ; 1.1 P$ : precipitation increased by $10 \%$. For the reference case \pm 1 SD of the interannual variability is shown

\begin{tabular}{|lcccccc|}
\hline & Reference & $T+1$ & $q+1$ & $U-1$ & $0.9 c l$ & $1.1 P$ \\
\hline$P\left(\mathrm{~mm} \mathrm{yr}^{-1}\right)$ & $596 \pm 60$ & 596 & 596 & 596 & 596 & 655 \\
$E\left(\mathrm{~mm} \mathrm{yr}^{-1}\right)$ & $467 \pm 55$ & 499 & 301 & 446 & 485 & 467 \\
$P-E\left(\mathrm{~mm} \mathrm{yr}^{-1}\right)$ & $129 \pm 84$ & 97 & 295 & 150 & 111 & 189 \\
$P-E\left(\mathrm{~m}^{3} \mathrm{~s}^{-1}\right)$ & $1527 \pm 994$ & 1147 & 3500 & 1774 & 1313 & 2238 \\
\hline
\end{tabular}

cloudiness result in minor changes in the long-term mean of $P-E$. The increased precipitation has a negligible effect on the SST and the evaporation calculations.

The net precipitation obtained in the reference case, about $1500 \mathrm{~m}^{3} \mathrm{~s}^{-1}$, agrees fairly closely with what was calculated in Omstedt \& Rutgersson (2000) and in Omstedt et al. (1997) (1800 to $1900 \mathrm{~m}^{3} \mathrm{~s}^{-1}$ ). In HELCOM (1986) an even smaller value of $P-E$ was obtained, but in that study a drier period (1951-1971) was investigated while the very wet 1980 s were not included.

In Omstedt \& Axell (1998) the salinity in PROBEBaltic was shown to agree well with measured data. The importance of having accurate freshwater input was also shown. An error of $2000 \mathrm{~m}^{3} \mathrm{~s}^{-1}$ changes the salinity of the Baltic Sea by about $1 \%$. It is likely that the upper limit in this study overestimates $P-E$ for the studied period. The upper limit of the sensitivity study represents an increase in $q$ of $1 \mathrm{~g} \mathrm{~kg}^{-1}$ over the entire Baltic Sea for the whole 18 yr period. This is probably valid at some synoptic stations during parts of the year, but likely an overestimation in general. A more realistic upper limit for $P-E$ is therefore estimated to be significantly below $3000 \mathrm{~m}^{3} \mathrm{~s}^{-1}$. The lower limit in the sensitivity tests comes close to the HELCOM value of about $1000 \mathrm{~m}^{3} \mathrm{~s}^{-1}$, representing a drier period. Realistic lower and upper limits for $P-E$ over the investigated $18 \mathrm{yr}$ are therefore estimated to be 1100 and $2500 \mathrm{~m}^{3} \mathrm{~s}^{-1}$ (or 100 to slightly above $200 \mathrm{~mm} \mathrm{yr}^{-1}$ ), where the upper limit is based on subjective judgement.

\subsection{Inter-annual variability}

The inter-annual variability in calculated $P, E$ and $P-E$ is illustrated in Fig. 5. The variability is somewhat larger for precipitation than for evaporation. The highest annual precipitation was found for 1981 and 1998, with values of 752 and $694 \mathrm{~mm}$ respectively, while the lowest annual precipitation was $496 \mathrm{~mm}$ in 1982. The lowest evaporation was $330 \mathrm{~mm}$, occurring in 1987, a year with severe ice conditions. The highest net precipitation thus occurred in 1981, 1987, and 1998, and the lowest in 1983 and 1989, with annual values ranging from 27 to $299 \mathrm{~mm}$. Including the range of estimated errors of the meteorological forcing (see Section 2.1), annual values of net precipitation range between -14 and $456 \mathrm{~mm}$ (from minimum to maximum annual values in Fig. 5), but as discussed above, the upper limit appears unrealistic as a climate mean. From these calculations we estimate that the interannual variability of net precipitation may range from almost 0 to $350 \mathrm{~mm}$ or $4000 \mathrm{~m}^{3} \mathrm{~s}^{-1}$. 

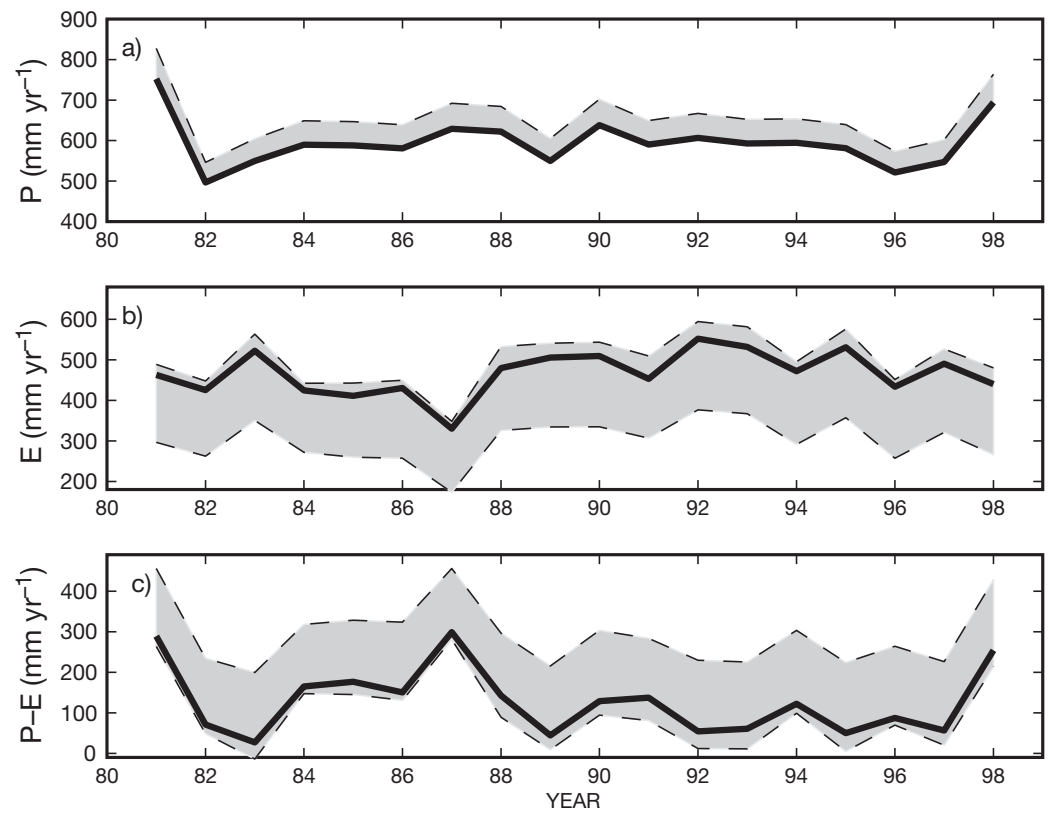

Fig. 5. Inter-annual variability of (a) precipitation, (b) evaporation, and (c) net precipitation for $18 \mathrm{yr}$. Shaded area: estimated uncertainty range using the different meteorological forcing; thick solid line: reference model run

\subsection{Regional variability}

There are also significant regional variations in $P-E$ over the Baltic Sea. The average regional values are shown in Fig. 7 and Table 6. $P$ varies within a range of $100 \mathrm{~mm}$ $\mathrm{yr}^{-1}$ for the different basins, with maximum values in the Gulfs of Riga and Finland (basins 7 and 8) and a minimum in the North Western Gotland Basin (basin 6). E has a range of nearly $300 \mathrm{~mm} \mathrm{yr}^{-1}$, with highest values in the southern and lowest values in the northern parts of the Baltic Sea. This is mainly explained by the differences in sea ice coverage between the northern and the southern sub-basins, and also by the fact that the southern parts are generally warmer, resulting in higher $E$. The resulting long-term $P-E$ varies regionally from $-1 \mathrm{~mm}$ in the Arkona Basin up to $272 \mathrm{~mm}$ in the Bothnian Sea. It is noteworthy that, without the significant ice cover of the northern parts of the Baltic Sea (basins $7-10)$, the yearly average $P-E$ would approach zero. In the sensitivity tests, the

\subsection{Seasonal cycle}

The seasonal cycle as represented by monthly means for the studied $18 \mathrm{yr}$ period is shown in Fig. 6 and Table 5 . The variability as well as the mean values are largest in the summer and early autumn for $P$, and in the autumn for $E$. This results in maximum $P-E$ from May to July and small, even negative values, during the autumn. In individual years, the monthly values can be substantially higher or lower than these averages (see Fig. 6).

Regarding the sensitivity test (Table 5), the humidity case, $q+1$, is responsible for the largest effect on $E$ also in the monthly values. The difference when changing the humidity is largest during late autumn, due to higher wind speeds and unstable conditions. The temperature change produces the largest effect during the summer due to the saturation relation, which has a stronger effect at higher temperatures. The change in wind speed has the greatest effect during the late autumn when $E$ is largest. Reduced cloudiness increases both short-wave radiation reaching the surface and cooling by longwave radiation. The net effect on $E$ is an increase in summer, when solar radiation is strongest, and a slight decrease in winter. The impact on the annual mean is, however, small.
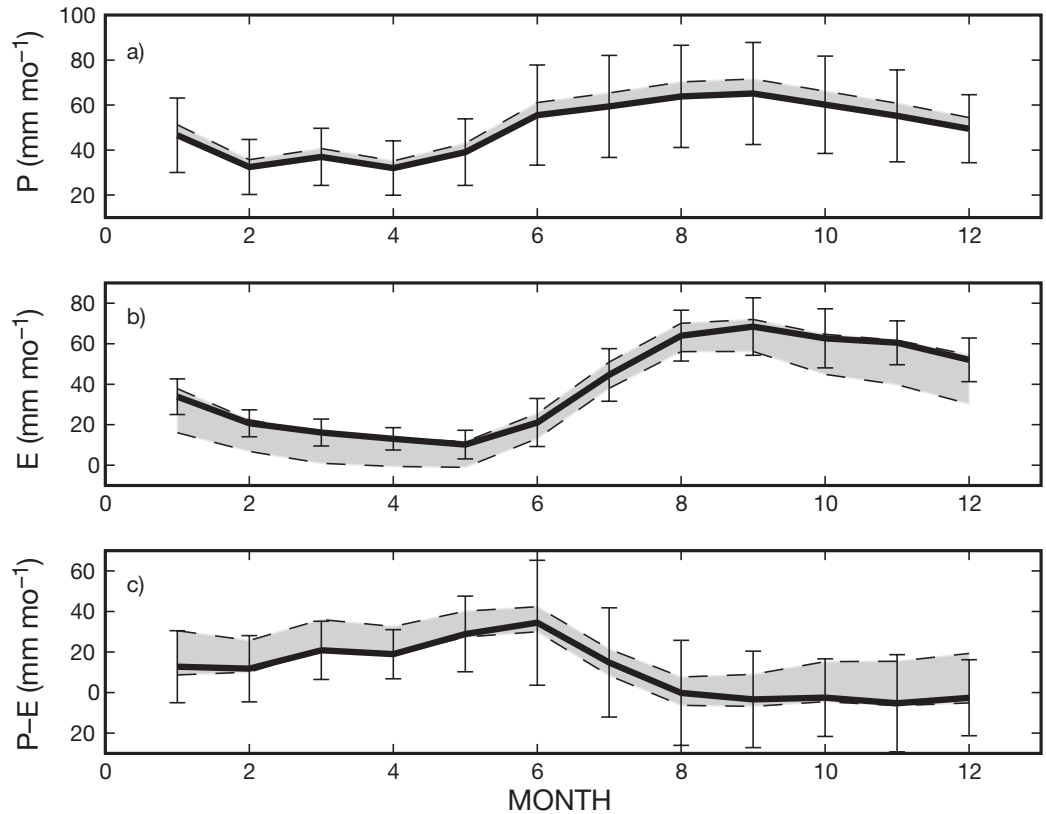

Fig. 6. Monthly mean values of (a) precipitation, (b) evaporation, and (c) net precipitation for $18 \mathrm{yr}$. Shaded area and thick solid line as in Fig. 5. Bars represent $\pm 1 \mathrm{SD}$ of the inter-annual variability for each month 
Table 5. Monthly mean net precipitation for the $18 \mathrm{yr}$ sensitivity tests. The different cases are explained in Section 2.1

\begin{tabular}{|lrrrrrr|}
\hline & Reference & $T+1$ & $q+1$ & $U-1$ & $0.9 c l$ & $1.1 P$ \\
\hline$\left(\mathrm{mm} \mathrm{mo}^{-1}\right)$ & & & & & & \\
Jan & 13 & 9 & 30 & 16 & 14 & 17 \\
Feb & 12 & 10 & 26 & 15 & 13 & 15 \\
Mar & 21 & 21 & 36 & 23 & 22 & 25 \\
Apr & 19 & 19 & 33 & 21 & 19 & 22 \\
May & 29 & 27 & 40 & 28 & 28 & 33 \\
Jun & 34 & 30 & 42 & 30 & 31 & 40 \\
Jul & 15 & 9 & 21 & 12 & 8 & 21 \\
Aug & 0 & -5 & 8 & 1 & -6 & 6 \\
Sep & -3 & -7 & 9 & 0 & -7 & 3 \\
Oct & -3 & -4 & 15 & 1 & -4 & 4 \\
Nov & -5 & -6 & 15 & 0 & -5 & 0 \\
Dec & -3 & -5 & 19 & 3 & -2 & 2 \\
& & & & & & \\
\hline
\end{tabular}

\subsection{Long-term variability}

River runoff from the land area of the Baltic drainage basin (see Fig. 1) represents $P-E$ over land. The land area is about 4 times as large as the Baltic Sea surface, but the net water transport is 1 order of magnitude larger over land compared to the sea surface (the total runoff is of the order of $15000 \mathrm{~m}^{3} \mathrm{~s}^{-1}$; Bergström \& Carlsson 1994). The higher $P-E$ over land can be explained by more precipitation over land and more evaporation over sea.

On a larger scale, the river runoff from the Baltic drainage basin is related to the $P-E$ over the Baltic Sea. The large scales of atmospheric circulation and major weather systems result in similar $P$ patterns and qualitatively similar temperature anomalies over the land area and over the Baltic Sea. As sea ice significantly reduces $E$ over the sea (Omstedt et al. 1997), one should also expect that large-scale $P-E$ over the Baltic Sea is related to sea ice. Since we have a long time series of river runoff and maximum ice extent data, one may analyse these data sets in relation to $P-E$ and estimate the long-term variability. This idea is explored below.

Based on the monthly mean distribution of total river runoff to the Baltic Sea $\left(Q_{\mathrm{f}}\right)$ and $P-E$ using the $18 \mathrm{yr}$ of PROBE Baltic data, we can observe an approximately 1 mo delay in $Q_{\mathrm{f}}$ compared to $P-E$. We therefore relate annual $P-E$ to annual $Q_{\mathrm{f}}$ with a 1 mo delay. Using annual values, the correlation between these 2 parameters for the $18 \mathrm{yr}$ of data is $r_{0}=0.71$. The Baltic Sea is covered with ice for large parts of the year, signifi-
Table 6. Basin averages of net precipitation for the $18 \mathrm{yr}$ period of the sensitivity tests. The different basins B3 to B10 are explained in Fig. 2

\begin{tabular}{|lrrrrrr|}
\hline & Reference & $T+1$ & $q+1$ & $U-1$ & $0.9 C l$ & $1.1 P$ \\
\hline B3 & -1 & -38 & 172 & 46 & -23 & 59 \\
B4 & 34 & 6 & 218 & 65 & 12 & 94 \\
B5 & 49 & 19 & 228 & 59 & 27 & 110 \\
B6 & 18 & -17 & 202 & 27 & -1 & 74 \\
B7 & 157 & 113 & 305 & 183 & 138 & 224 \\
B8 & 264 & 229 & 433 & 272 & 250 & 332 \\
B9 & 272 & 240 & 415 & 304 & 260 & 332 \\
B10 & 251 & 230 & 398 & 281 & 238 & 309 \\
& & & & & & \\
\hline
\end{tabular}

cantly reducing $E$ over sea. When also including maximum ice extent $\left(A_{\text {ice }}\right)$ in the linear regression the correlation with the $P-E$ increases to $\mathrm{r}_{0}=0.82$, which is a significant improvement. The following regression relationship is obtained, where $(P-E)^{\prime}, Q_{\mathrm{f}}^{\prime}$ and $A_{\text {ice }}^{\prime}$ denote the anomalies of net precipitation, river runoff and maximum ice extent with the respect to their mean values for the 1981 to 1998 period $\left(\overline{P-E}=1527, \bar{Q}_{\mathrm{f}}=\right.$ 15011 and $\overline{A_{\text {ice }}}=175$ ):

$$
(P-E)^{\prime}=a Q_{\mathrm{f}}^{\prime}+b A_{\text {ice }}^{\prime}\left(\mathrm{m}^{3} \mathrm{~s}^{-1}\right)
$$

where $a=3.8803$ and $b=0.5266$. Fig. 8 illustrates the annual Baltic Sea $P-E$ using the reference case from Section 4.2 (Fig. 5) and the values from Eq. (1). This
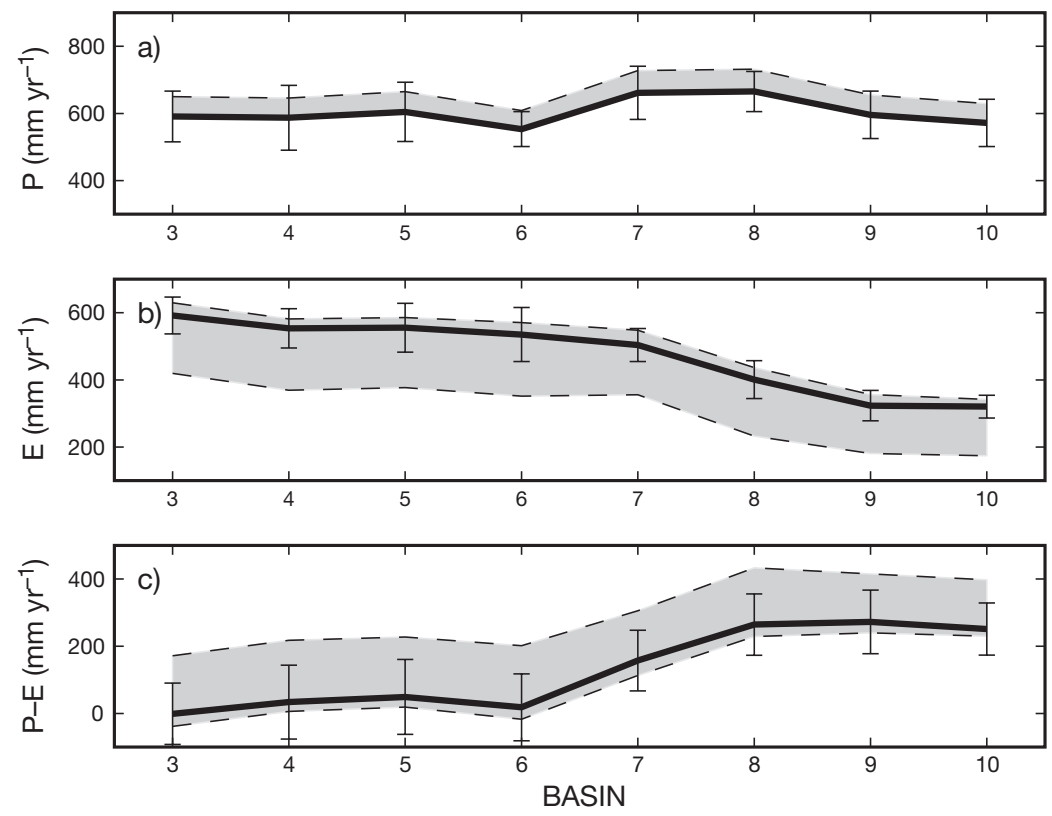

Fig. 7. Regional variability of the 18 yr mean of (a) precipitation, (b) evaporation, and (c) net precipitation for the different basins described in Fig. 2. Shaded area and thick solid line as in Fig. 5. Bars represent \pm 1 SD of the inter-annual variability for each basin 
regression allows a rough estimate of $P-E$ for periods where we have no data, other than on $Q_{\mathrm{f}}$ and $A_{\text {ice }}$.

Using this method with information on $Q_{\mathrm{f}}$ and $A_{\text {ice }}$ for the 1901-1998 period gives a long-term climate average value for net precipitation of $(P-E)_{\text {climate }}=1152 \pm 874 \mathrm{~m}^{3} \mathrm{~s}^{-1}$, where 874 is $1 \mathrm{SD}$ of the interannual variability. This long-term climate value is lower than that calculated by PROBE-Baltic for 1981-1998, indicating that the last 18 yr were wetter than the century as a whole. In Fig. 9 the measured annual values for $Q_{\mathrm{f}}, A_{\text {ice }}$ and $P-E$ from Eq. (1) are shown together with the 10 yr running mean. The last $10 \mathrm{yr}$ are relatively wet and with less ice than the longterm mean. The relatively high $P-E$ is, however, not unique; similar values are estimated for the 1920s.

From these and the earlier calculations we estimate the long-term mean $P-E$ for the 20th century climate to be $1500 \pm$ $1000 \mathrm{~m}^{3} \mathrm{~s}^{-1}$.
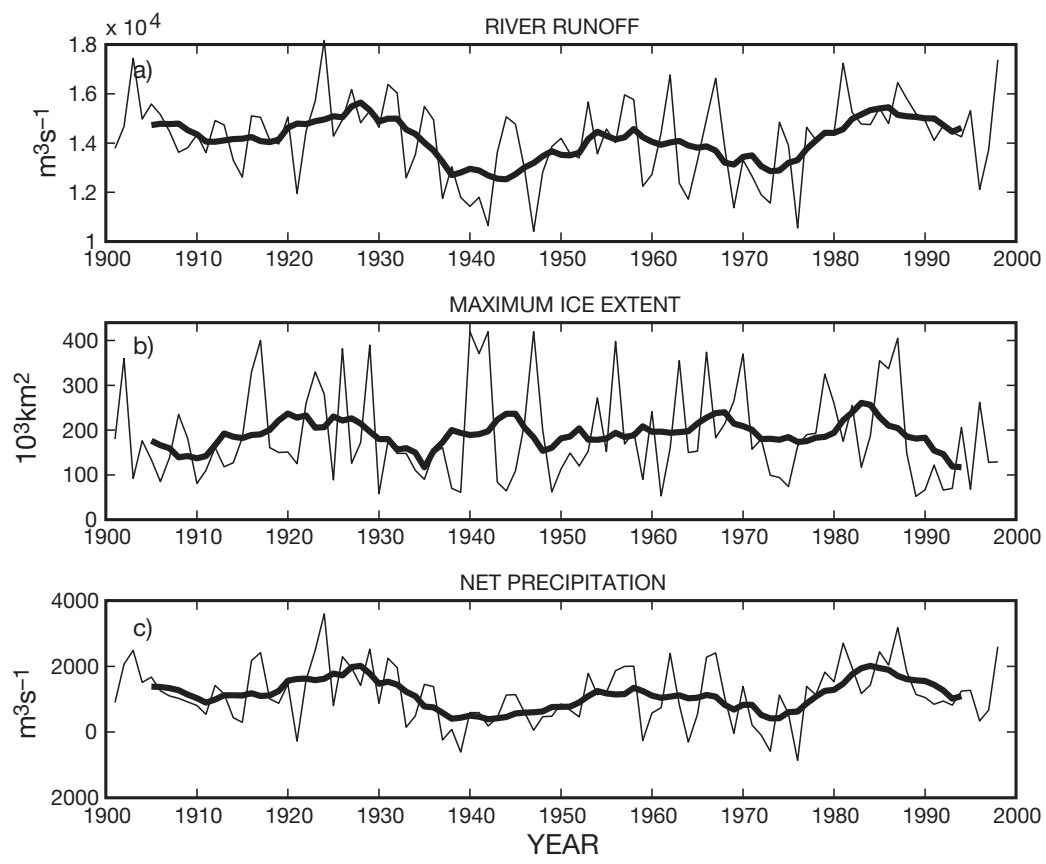

Fig. 9. (a) River runoff and (b) maximum ice extent from measured data, and (c) net precipitation from Eq. (1) for 1901-1998. Thin lines: annual values; thick lines: 10 yr running mean

\section{NET PRECIPITATION IN REGIONAL CLIMATE MODEL SIMULATIONS}

To investigate possible future changes in the $P-E$, 2 regional climate change experiments are studied. These experiments were made with the RCA1 version of the Rossby Centre regional climate model for northern and central Europe (Rummukainen et al. 2001), using $44 \mathrm{~km}$ horizontal resolution and boundary data

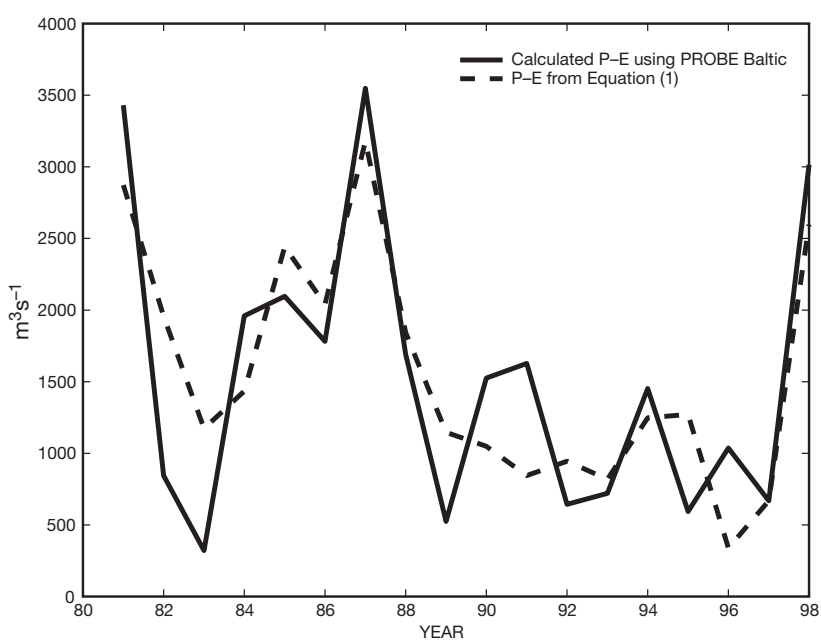

Fig. 8. Net precipitation, modelled by PROBE-Baltic and estimated using river runoff and ice extent data according to Eq. (1). Thick solid line: PROBE-Baltic simulation; dashed line: $P-E$ estimated using river runoff and maximum ice extent from 2 global climate models: HadCM2 and ECHAM4. The PROBE-Baltic ocean model is included as an interactive component in RCA1.

The 2 RCA1 experiments are denoted, according to the driving models, as RCA-H and RCA-E. Each of them consists of a $10 \mathrm{yr}$ control run and a $10 \mathrm{yr}$ scenario run with higher greenhouse gas concentrations but with no other types of anthropogenic forcing such as sulphate aerosols. The boundary data for RCA-H are from partial reruns of 2 long HadCM2 simulations described by Mitchell \& Johns (1997); that is, a control run and a transient greenhouse run, in which gradually increasing $\mathrm{CO}_{2}$ represents the change in greenhouse forcing from the pre-industrial era. The period used from the HadCM2 greenhouse run is 2039-2049. The RCA-E boundary forcing data are from a presentday (nominally 1980s) and a future (2070s) time slice from a transient ECHAM4 greenhouse run (Roeckner et al. 1999). RCA-H and RCA-E therefore differ in terms of the periods, and this is also the case with the greenhouse-gas-induced radiative forcing in the driving GCMs. The forcing in HadCM2, resulting from a $150 \%$ increase in $\mathrm{CO}_{2}$, is about $20 \%$ larger than that in ECHAM4, in which increases are described for several greenhouse gases separately (Fig. 0.3 of Machenhauer et al. 1998). However, the global mean surface air warming between the 2 time slices is almost the same $\left(2.6^{\circ} \mathrm{C}\right)$ in both of the $2 \mathrm{GCMs}$. This is in the midway of the IPCC (2001) uncertainty range $\left(1.4\right.$ to $\left.5.8^{\circ} \mathrm{C}\right)$ for global mean warming between 1990 and 2100 . 
The $P-E$ results for the present-day climate in RCA$\mathrm{H}$ and RCA-E are investigated in Table 7 and Fig. 10.

Both control runs have higher $P$ than the present reference results, especially RCA-E. High $P$ in northern Europe is a common feature also in global climate models (Räisänen 2000), tending to be amplified in regional models, in which higher resolution leads to more intense vertical motions (e.g. Jones et al. 1995, Christensen et al. 1998).

Ultimately, weaknesses in model parameterisations and inconsistencies in these between global and regional models are at play. The difference between RCA-H and RCA-E parallels a similar difference between the 2 driving models and is probably related both to differences in atmospheric circulation and to the temperatures inherited from ECHAM4 which are warmer than those from HadCM2. $P$ is higher in RCA$\mathrm{E}$ than in RCA-H but shows a more realistic seasonal cycle.

The low year-round $E$ in both control simulations can be explained by a cold bias in the near-surface temperatures (Rummukainen et al. 2001) and by an overly humid surface layer over the sea. The cold bias is seen in Fig. 11, where monthly averages of the SST in 3 of the ocean basins within the Baltic Sea are shown (see Fig. 2 for the definition of the basins).
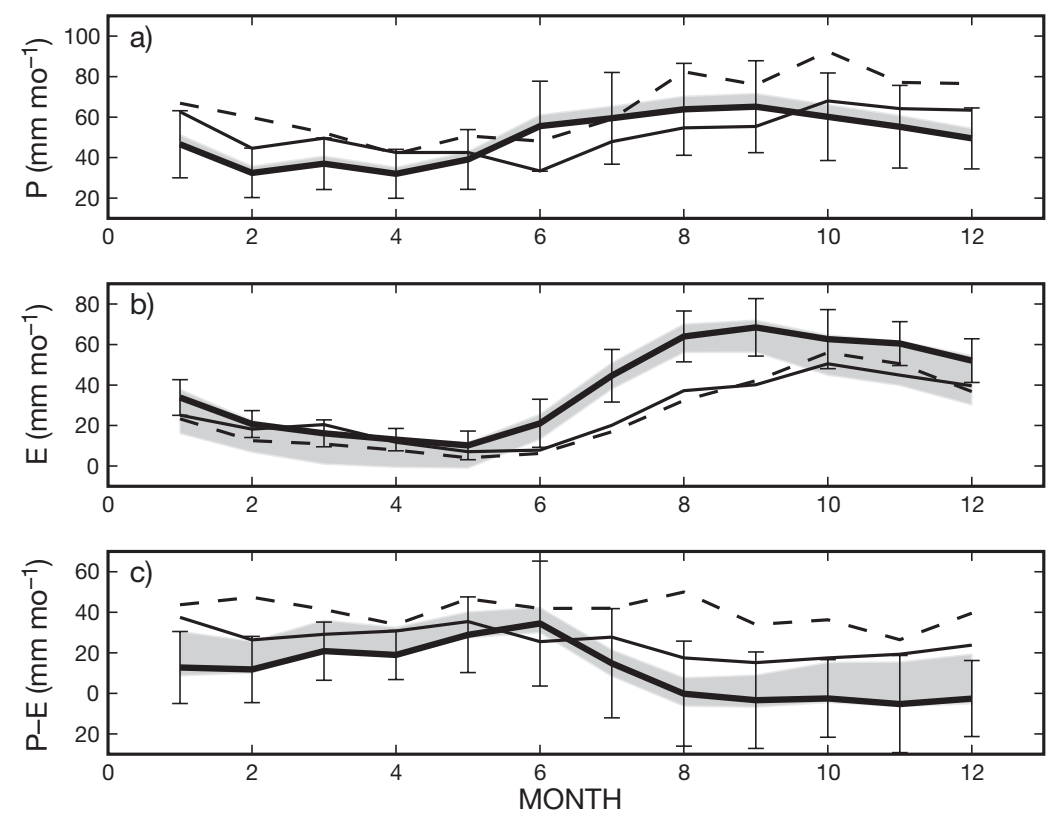

Fig. 10. Monthly averages from 2 different simulations of present-day climate with the regional RCA1 model. Thin solid line: use of data from the HADCM2 model at the boundaries (RCA-H); dashed line: use of data from ECHAM4 on the boundaries (RCA-E). Ten-year averages are used for the 2 RCA runs. Thick solid line: reference run using PROBE-Baltic for $18 \mathrm{yr}$ as discussed earlier (the shaded area is the range of sensitivity tests and error bars $\pm 1 \mathrm{SD}$ of the annual variability in PROBE-Baltic). (a) Precipitation, (b) evaporation, and (c) net precipitation
Table 7. Annual averages of precipitation, evaporation, and net precipitation from the RCA model with 2 different forcing models, representing the present-day climate (RCA-H ctr and RCA-E ctr respectively). The reference case is from the PROBE-Baltic model using the meteorological forcing from the $\operatorname{SMHI}(1 \times 1)^{\circ}$ database as in Section 4. The 20th century estimate is discussed in Section 4.5

\begin{tabular}{|lcccc|}
\hline & 20th century & Reference & RCA-H ctr & RCA-E ctr \\
\hline$P\left(\mathrm{~mm} \mathrm{yr}^{-1}\right)$ & & 596 & 629 & 783 \\
$E\left(\mathrm{~mm} \mathrm{yr}^{-1}\right)$ & & 467 & 323 & 300 \\
$P-E\left(\mathrm{~mm} \mathrm{yr}^{-1}\right)$ & $127 \pm 85$ & 129 & 306 & 483 \\
$P-E\left(\mathrm{~m}^{3} \mathrm{~s}^{-1}\right)$ & $1500 \pm 1000$ & 1527 & 3603 & 5687 \\
\hline
\end{tabular}

The PROBE-Baltic reference run and the 2 control climate simulations are shown together with observed SSTs from ship cruises. The 2 RCA-simulations are generally colder than the observations; this is especially clear in the case of RCA-H. Atmospheric humidity is a crucial parameter determining E. In Fig. 12 monthly averages of the relative humidity from RCA$\mathrm{H}, \mathrm{RCA}-\mathrm{E}$, and the $\mathrm{SMHI}(1 \times 1)^{\circ}$ database at $2 \mathrm{~m}$ are shown. The relative humidity is significantly higher in the 2 RCA simulations than in the $\operatorname{SMHI}(1 \times 1)^{\circ}$ database. This can to a large extent explain the lower $E$ in RCA-H and RCA-E. The humid surface layers in RCA$\mathrm{H}$ and RCA-E give less $E$. The difference in relative humidity is largest during the spring, but the effect on $E$ can mainly be seen during the autumn, when $E$ is highest. It should here be remembered that the humidity in the SMHI $(1 \times 1)^{\circ}$ database could be too low compared to measurements (see Table 1) and thus the error in the models may not be as large as the difference in Fig. 12.

The high $P$ together with low $E$ gives unrealistically high $P-E$ values, which are up to 4 times the estimate from Section 4. Even though the monthly values lie partly within $1 \mathrm{SD}$ of the PROBE-Baltic simulation, the annual mean values are significantly higher than a realistic upper range. In Fig. 10 we are comparing the two $10 \mathrm{yr}$ time slice experiment simulations with the investigated $18 \mathrm{yr}$ period, but the difference is even larger when comparing with the 100 yr climate value from Section 4. There is little or no seasonal $P-E$ cycle in RCA-H and RCA-E due to the small seasonal $P$ cycle. From this we can conclude that the climate model overestimates $P-E$ and does not properly reproduce the seasonal cycle. Thus, the modelling of the water cycle needs considerable improvement.

The simulated greenhouse-gas-induced changes of $P-E$ in the Baltic Sea are shown 

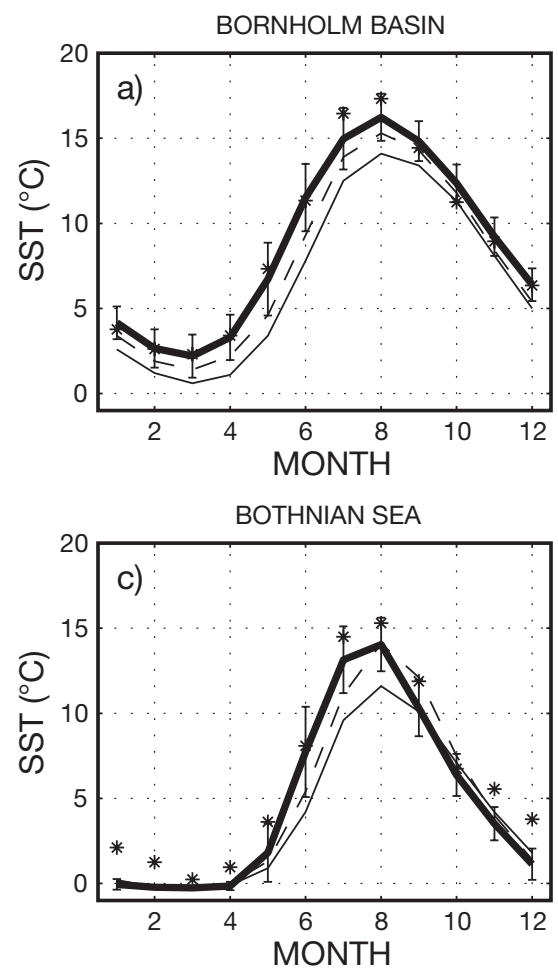

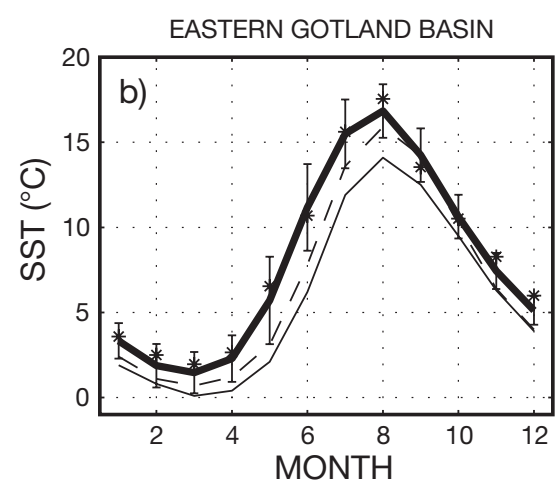

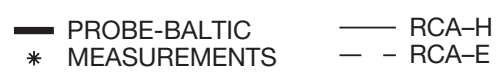

Fig. 11. Monthly mean SST in (a) Bornholm Basin, (b) Eastern Gotland Basin, and (c) Bothnian Sea. Thick solid line: 18 yr PROBE-Baltic simulation, also including $\pm 1 \mathrm{SD}$ of the annual variability. Stars: measurements used in Fig. 3 and Table 2; thin solid line: 10 yr control simulation using $\mathrm{RCA}-\mathrm{H}_{\text {; }}$ dashed line: $10 \mathrm{yr}$ control simulation using RCA-E ration, or long-term runoff). The $P-E$ over land is higher in the control simulations than the value given by Bergström \& Carlsson (1994), which can also be explained by too high $P$.

However, the $P-E$ overestimation per unit area is smaller over land than over sea. According to the databases used in this study, $P-E$ is, per unit area, more than twice as large over land as over sea. In the RCA simulations the difference is relatively small or zero.

It is noteworthy that $E$ (or evapotranspiration) is larger per unit area over land than over sea in the climate model (not shown). This is contrary to what can be expected, since there is usually a limitation in the availability of water over land. This difference can probably be explained by too much weak $P$ resulting in a too humid surface which leads to increased evapo-

in Table 8. $P$ increases in both simulations, with 106 and $74 \mathrm{~mm} \mathrm{yr}^{-1}$ respectively. Due to warming, which amounts to over $3^{\circ} \mathrm{C}$ in the annual mean, there is also a smaller increase in $E(37$ and $66 \mathrm{~mm} \mathrm{yr}^{-1}$ respectively). The change in $P-E$ for a changed climate is, according to these simulations, relatively small $(70$ and $8 \mathrm{~mm} \mathrm{yr}^{-1}$ for RCA-H and RCA-E respectively). This indicates that increased $P$ could be at least partly compensated for by increased $E$ in a warmer climate. But the degree of this compensation differs between the different model runs.

The warming results in higher SST and thus also a significant reduction in ice cover, which can be seen in Table 9. Increased greenhouse gases will, for these simulations, result in an average annual maximum ice cover only slightly larger than the climatological minimum value of $52 \times 10^{3} \mathrm{~km}^{2}$.

In Table 10 the annual averages of the Baltic Sea $P-E$ are compared with $P-E$ over the drainage basin (precipitation minus evapotranspi-
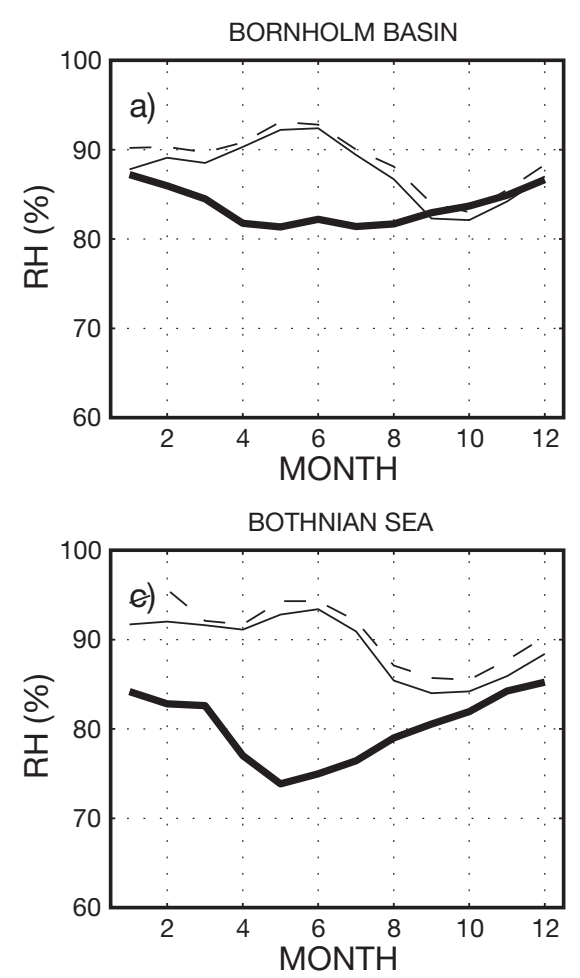

transpiration over land (since the surface then never dries), and a decreased $E$ over sea, which was seen in Fig. 12.

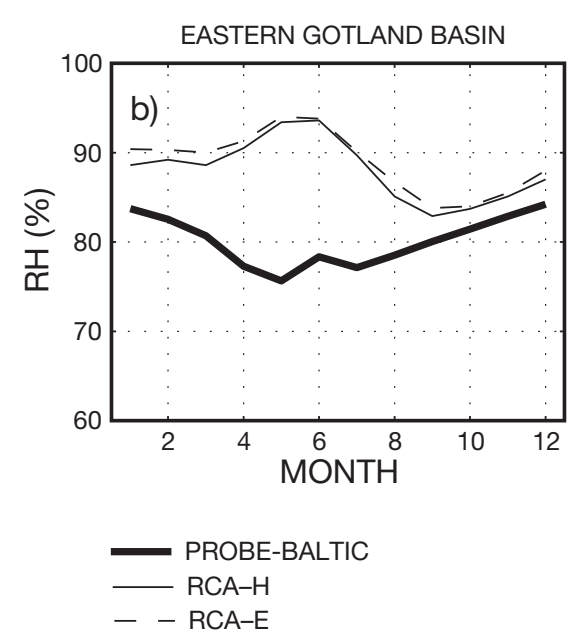

Fig. 12. Monthly mean relative humidity in (a) Bornholm Basin, (b) Eastern Gotland Basin, and (c) Bothnian Sea. Thick solid line: from the $\operatorname{SMHI}(1 \times 1)^{\circ}$ database; thin solid line: 10 yr control simulation using $\mathrm{RCA}-\mathrm{H}$; dashed line: $10 \mathrm{yr}$ control simulation using RCA-E 
Table 8. Annual averages of precipitation, evaporation, and net precipitation from the RCA model with 2 different forcings for higher greenhouse concentrations (RCA-H scn and RCA-E scn respectively) The differences between the control and scenario simulations are shown in parentheses

\begin{tabular}{|lcc|}
\hline & RCA-H scn & RCA-E scn \\
\hline$P\left(\mathrm{~mm} \mathrm{yr}^{-1}\right)$ & $735(106)$ & $857(74)$ \\
$E\left(\mathrm{~mm} \mathrm{yr}^{-1}\right)$ & $360(37)$ & $366(66)$ \\
$P-E\left(\mathrm{~mm} \mathrm{yr}^{-1}\right)$ & $375(69)$ & $491(8)$ \\
$P-E\left(\mathrm{~m}^{3} \mathrm{~s}^{-1}\right)$ & $4416(813)$ & $5781(94)$ \\
\hline
\end{tabular}

Table 9. Averaged annual maximal ice extent for the $10 \mathrm{yr}$ simulations, also showing $\pm 1 \mathrm{SD}$ of the inter-annual variability

\begin{tabular}{|lr|}
\hline $\begin{array}{l}\text { Run } \\
\left(10^{3} \mathrm{~km}^{2}\right)\end{array}$ & \multicolumn{1}{c|}{$A_{\text {ice max }}$} \\
\hline RCA-H, CTRL & $248.0 \pm 76.2$ \\
RCA-E, CTRL & $220.2 \pm 84.1$ \\
RCA-H, SCEN & $105.9 \pm 67.0$ \\
RCA-E, SCEN & $74.6 \pm 67.6$ \\
& \\
\hline
\end{tabular}

$P-E$ is larger in the scenarios than the control runs also over land areas, although increased $P$ is partly balanced by increased $E$.

\section{SUMMARY AND CONCLUSIONS}

The current work analyses $P-E$ over the Baltic Sea over an 18 yr period using a gridded meteorological database and a Baltic Sea ocean model. Several aspects of the $P-E$ were investigated: inter-annual, seasonal, and regional variability, as well as sensitivity to errors in the meteorological forcing.

Baltic Sea $P-E$ is shown to be sensitive to meteorological forcing. It is mainly near-surface humidity and $P$ which are of importance, and an increase of specific humidity of $1 \mathrm{~g} \mathrm{~kg}^{-1}$ increases $P-E$ by over a

Table 10. Net precipitation over the Baltic Sea and total river runoff to the Baltic Sea

\begin{tabular}{|lcccc|}
\hline Run & $\begin{array}{c}\text { Baltic Sea } \\
\left(\mathrm{m}^{3} \mathrm{~s}^{-1}\right)\end{array}$ & $\begin{array}{c}\text { Runoff area } \\
\left(\mathrm{m}^{3} \mathrm{~s}^{-1}\right)\end{array}$ & $\begin{array}{c}\text { Baltic Sea } \\
\left(\mathrm{mm} \mathrm{yr}^{-1}\right)\end{array}$ & $\begin{array}{c}\text { Runoff area } \\
\left(\mathrm{mm} \mathrm{yr}^{-1}\right)\end{array}$ \\
\hline RCA-H, CTRL & 3603 & 18933 & 306 & 370 \\
RCA-E, CTRL & 5687 & 24644 & 483 & 482 \\
RCA-H, SCEN & 4416 & 23896 & 375 & 467 \\
RCA-E, SCEN & 5781 & 26455 & 491 & 517 \\
Reference & 1527 & $15310^{\mathrm{a}}$ & 129 & $299^{\mathrm{a}}$ \\
aFrom Bergström \& Carlsson (1994) & & \\
\hline
\end{tabular}

factor of 2. Temperature is also relatively important, mainly since it affects the $E$ efficiency and the ice cover. Other parameters such as wind speed and cloudiness are of less importance. It is important to include ice in the calculations, due to its strong reduction of $E$. When looking only at ice-free basins $P-E$ approaches zero.

An advantage of using an ocean model to estimate $P-E$ is the consistency check provided by simulated salinity. An error of $2000 \mathrm{~m}^{3} \mathrm{~s}^{-1}$ in $P-E$ changes the salinity by about $1 \%$. The salinity in the ocean model reference simulation agrees well with measured data, and it is therefore likely that the $P-E$ is close to, or only slightly higher than, that which is found in the reference case.

The relation between Baltic Sea $P-E$, river runoff, and maximum ice extent was investigated to estimate $P-E$ earlier in the century, when we have little direct information about $P$ and $E$. By such a regression method, $P-E$ was calculated for a period of nearly $100 \mathrm{yr}$. This value was close to the lower limit of the 18 yr sensitivity test with the ocean model, indicating that the $18 \mathrm{yr}$ period was wetter than the $100 \mathrm{yr}$ climate mean.

The analysis of $P-E$ in the 2 climate model experiments showed a significant overestimation of $P-E$ in the model simulations of present-day climate when compared both to the $100 \mathrm{yr}$ climate value and the 18 yr ocean model simulation. This is partly due to high $P$ and partly due to low $E$ in the model, mainly during the summer. The low $E$ can be explained by a cold bias in the model and by a too humid layer near the surface. A too low temperature results in less efficient $E$, as well as reduced $E$ due to increased ice cover. The humid lower layer may be related to the high evapotranspiration found over land areas, which is likely advected over sea.

$P$ increased in the 2 simulations with increased greenhouse gases, as did $E$ due to warmer climate and reduced ice. The net effect for a changed climate is thus, for the present 2 simulations, relatively small due to the compensating effects.

The conclusions from this work can be briefly summarised:

- Net precipitation over the Baltic Sea, when analysed with a process-oriented ocean model and a gridded synoptic database, is sensitive to precipitation and humidity in the near-surface layer and also to ice cover. The $18 \mathrm{yr}$ annual mean value lies within the 1100 to $2500 \mathrm{~m}^{3} \mathrm{~s}^{-1}$ range, based on sensitivity tests and subjective judgement. The reference value was about $1500 \mathrm{~m}^{3} \mathrm{~s}^{-1}$. Estimates of net precipitation using 
almost 100 yr of river runoff and ice-extent data give a lower mean value of about $1200 \mathrm{~m}^{3} \mathrm{~s}^{-1}$. The investigated 18 yr period is thus wetter than the long-term mean. A mean value for net precipitation over the Baltic Sea during present climate conditions can thus be assumed to be $1500 \pm 1000 \mathrm{~m}^{3} \mathrm{~s}^{-1}$. The interannual variability is, however, quite large.

- Using 2 different simulations with a regional climate model for the present-day climate showed that considerable improvements are needed in the modelling of both precipitation and evaporation. The amount of net precipitation in both simulations was overly high and the seasonal cycle was not captured. Furthermore, the land-sea contrast in net precipitation was too small.

- Simulations of a changed climate when increasing the amount of greenhouse gases resulted in a relatively small increase in net precipitation when related to present day simulations. This is because, in the simulations, increased precipitation was partly compensated for by increased evaporation due to the warmer climate. This is especially true for the run driven by ECHAM4, while in the run driven by HadCM2 the increase in net precipitation is larger.

Acknowledgements. This work comprises part of SMHI's contribution to BALTEX and part of the Swedish Regional Climate Program, SWECLIM. The authors thank Jerzy Cyberski, Andrzej Wroblewski, and Bengt Carlsson for providing the river runoff data. We would also like to thank the anonymous reviewers for constructive comments.

\section{LITERATURE CITED}

BALTEX (1995) Baltic Sea Experiment BALTEX. Initial implementation plan. International BALTEX Secretariat 2, GKSS Research Center, Geesthacht

Bergström S, Carlsson B (1994) River runoff to the Baltic Sea: 1950-1990. Ambio 23:280-287

Christensen OB, Christensen JH, Machenhauer B, Botzet M (1998) Very high-resolution climate simulations over Scandinavia - present climate. J Clim 11:3204-3229

Cyberski J, Wroblewski A (2000) Riverine water inflows and the Baltic Sea water volume 1901-1990. Hydrol Earth Syst Sci 4:1-11

DeCosmo J, Katsaros KB, Smith SD, Anderson RJ, Oost WA, Bumke K, Chadwick H (1996) Air-sea exchange of water vapor and sensible heat: the HEXOS results. J Geophys Res 101:12001-12016

HELCOM (1986) Water balance of the Baltic Sea. Baltic Sea Environment Proceedings 16. Baltic Marine Environment Commission, Technical Research Centre of Finland, Helsinki

IPCC (2001) Climate change 2001. The science of climate change. Cambridge University Press, Cambridge

Jones RG, Murphy JM, Noguer M (1995) Simulation of climate over Europe using a nested regional-climate model. I: Assessment of control climate, including sensitivity to location of lateral boundaries. Q J R Meteorol Soc 121:1413-1449

Karlsson KG (2000) Satellite sensing techniques and applications for the purpose of BALTEX. Meteorol Z 9:111-116
Knudsen M (1899) De hydrografiske forhold i de danske farvande indenfor Skagen i 1894-98. (The hydrographic conditions in the Danish waters inside Skagen in 1894-98). Komm For Vidensk Unders I de danske farvande 2:2

Knudsen M (1900) Ein hydrographischer Lehrsatz. Ann Hydrol 28:316-320

Launiainen J (1995) Derivation of the relationship between the Obukhov stability parameter and the bulk Richardson number for flux profiles. Boundary-Layer Meteorol 76: 165-179

Machenhauer B, Windelband M, Botzet M, Christensen JH, Déqué M, Jones RG, Ruti P, Visconti G (1998) Validation and analysis of regional present-day climate and climate change simulations over Europe. Max-Planck-Institut für Meteorologie, Report No. 275, Hamburg

Mikulski Z (1982) River inflow to the Baltic Sea 1921-1975. Polish Academy of Sciences, Polish National Committee of the IHP, University of Warzaw, Faculty of Geography and Regional Studies

Mitchell JFB, Johns TC (1997) On modification of global warming by sulphate aerosols. J Clim 10:245-267

Omstedt A (1990) A coupled one-dimensional sea ice-ocean model applied to a semi-enclosed basin. Tellus 42A: 568-582

Omstedt A, Axell LB (1998) Modeling the seasonal, interannual, and long-term variations of salinity and temperature in the Baltic Proper. Tellus 50A:637-652

Omstedt A, Chen D (2001) Influence of atmospheric circulation on the maximum ice extent in the Baltic Sea. J Geophys Res 106:4493-4500

Omstedt A, Nyberg L (1996) Response of Baltic Sea ice to seasonal, interannual forcing and climate change. Tellus 48A: $644-662$

Omstedt A, Rutgersson A (2000) Closing the water and heat cycles of the Baltic Sea. Meteorol Z 9:57-64

Omstedt A, Meuller L, Nyberg L (1997) Interannual, seasonal and regional variations of precipitation and evaporation over the Baltic Sea. Ambio 26:484-492

Räisänen J (2000) $\mathrm{CO}_{2}$-induced climate change in northern Europe: comparison of 12 CMIP2 experiments. RMK 87, SMHI, Norrköping

Raschke E and 36 others (2001) Baltic Sea Experiment (BALTEX): a European contribution to the investigation of the energy and water cycle over a large drainage basin. Bull Am Meteorol Soc 82:2389-2414

Roeckner E, Bengtsson L, Feichter J, Lelieveld J, Rodhe H (1999) Transient climate change simulations with a coupled atmosphere-ocean GCM including the tropospheric sulfur cycle. J Clim 12:3004-3032

Rummukainen M, Räisänen J, Bringfelt B, Ullerstig A, Omstedt A, Willen U, Hansson U, Jones C (2001) A regional climate model for northern Europe: model description and results from the downscaling of two GCM control simulations. Clim Dyn 17:339-359

Rutgersson A, Smedman AS, Omstedt A (2001a) Measured and simulated latent and sensible heat fluxes at two marine sites in the Baltic Sea. Boundary-Layer Meteorol 99:53-84

Rutgersson A, Bumke K, Clemens M, Foltescu V, Lindau R, Michelson D, Omstedt A (2001b) Precipitation estimates over the Baltic Sea: present state of the art. Nordic Hydrol $32: 285-314$

Seinä A, Palosuo E (1993) The classification of the maximum annual extent of ice cover in the Baltic Sea 1720-1992. Meri 20:5-20 (in Finnish)

WAMDI (1988) The WAM model. A third generation ocean wave prediction model. J Phys Oceanogr 18:1775-1810 